\title{
Understanding Intention to Spread Anti-Rumors of Natural Disasters in Social Media
}

\author{
Min-Yi Chen, Qian-Jin Zong \\ School of Economics and Management \\ South China Normal University \\ Guangzhou, P. R. China
}

\author{
Yun-Qing Zhu \\ Department of Computer Science \\ Guangdong Agriculture Industry Business Polytechnic \\ Guangzhou, P. R. China
}

\begin{abstract}
The purpose of this study is to investigate users' intention of spreading anti-rumors of natural disasters in social media. Adopted from Technology Acceptance Model, the theoretical model was constructed. 196 questionnaires were collected. Descriptive statistics and Structural Equation Model were employed as the research methods. The main findings are as followings. Attitude has a significant positive effect on intention of spreading anti-rumors of natural disasters. Reputation has a significant positive impact on attitude and intention of spreading natural disasters. Perceived ease of use has no significant impact on attitude toward spreading anti-rumors of natural disasters.
\end{abstract}

Keywords-Rumors; Natural disasters; Rumor-dispelling; Social media

\section{INTRODUCTION}

In the promotion of Internet technology and the applications of web2.0, social media develops rapidly. Although social can support rapid communication and sharing of useful information, they can also facilitate the spread of rumors [1]. Especially, limited to current technologies and openness of social media, there are a large amount of rumors after natural disasters [2]. These rumors could seriously interfere with the formulation of disaster relief decisions and relief work [3]. Meanwhile, a large number of inflammatory and alarmist rumors could mislead the public, damage social stability, and even bring adverse effects to "secondary disasters". Therefore, it is particularly important to dispel the rumors after natural disasters. Most of the current researches focused on the factors of spreading rumors and use of technical tools to combat rumors of natural disasters in social media. Liu, et al. [4] developed a model of rumor retransmission on social media during disasters based on rumor theory and the elaboration likelihood model. They found that sender's credibility is the most important predictor of users' intention of rumor retransmission. And the attractiveness is the next most important predictor. Hashimoto, et al. [5] proposed a framework to detect the rumor information in social media. The proposed framework clarified topics in social media, visualized topic structures in time series variation. Then it extracted rumor candidates and searched related information from other media such as TV program, newspapers and so on in order to confirm the reliability of rumor candidates.

In the wake of natural disasters, it is necessary for more people to know the truth behind the rumors of natural disasters in social media. Therefore, it is very important to encourage people to disseminate anti-rumors of natural disasters in social media after natural disasters. Based on a modified Technology Acceptance Model (TAM) [6], this study investigated users' intention of spreading anti-rumors of natural disasters in social media.

\section{HyPOTHESES AND RESEARCH MODEL}

In the classic Technology Acceptance Model [6], attitude is the cause of the user's intention. A large number of studies of information systems use have shown that attitude has a significant positive effect on the behavioral intention of information system. Ajili, et al. [7] proposed that there is a significant causal correlation between attitude to use with intention to use. It is assumed that positive attitude is seen as the proximal determinant of intention. Therefore, we propose the following hypothesis:

H1: Attitude of social media users to spread anti-rumors of natural disasters has a significant positive effect on intention of spreading anti-rumors of natural disasters.

As a typical application of web2.0 technology, social media is also difficult to use. Adrian, et al. [8] found a positive effect of perceived ease of use on information systems users' attitude to accept the use of technology. A study conducted by McGowan, et al. [9] found that the main factors influencing a physician's usage of social media to share medical knowledge with other physicians were perceived ease of use and usefulness. If forwarding function of a social media is easy to use, then the user's attitude to refute rumors may be promoted. Therefore, this study proposes the hypothesis here:

H2: Perceived ease of use of forwarding function of social media significantly affects the user's attitude towards spreading anti-rumors of natural disasters.

Hoisl, et al. [10] found that status, reputation, power, acceptance, and glory are associated with the concept of social rewards and have been found to have significant effects on contribution behavior in a virtual community. Some researchers have demonstrated that extrinsic motivations, such as reputation, have significant effects on the intention to participate in video-sharing online communities [11], online discussion forums [12], Wikipedia [13], and online travel communities [14]. Therefore, we propose the following hypotheses: 
H3: Pursuit of reputation has significant positive impact on attitude of users to spread anti-rumors of natural disasters in social media.

H4: Pursuit of reputation significantly affects intention of users to spread anti-rumors of natural disasters in social media.

Based on the hypotheses above, we construct the research model as Fig.1 shown.

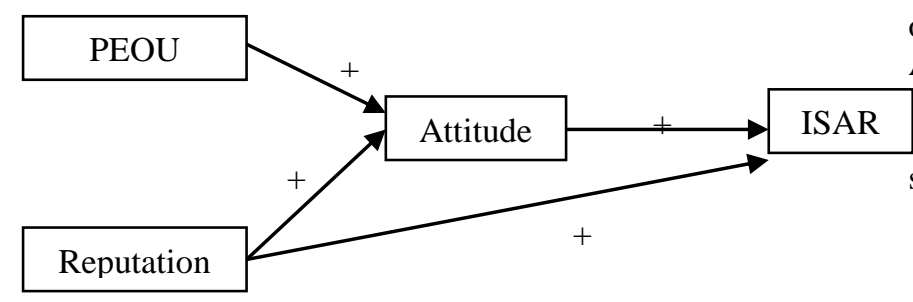

\section{METHODOLOGY}

There are two parts in the questionnaire. The first part comprises 12 questions to investigate the participants' perception and intention of spreading anti-rumors, and a 7point scale ranging from "strongly disagree" to "strongly agree" was used. All items of the first part were developed based on the previous researches. Adapted from the previous researches of information systems use $[6,15,16]$, the construct Intention of Spreading Anti-Rumors (ISAR), Attitude toward Spreading Anti-Rumors (Attitude) and Perceived Ease of Use (PEOU) were developed. The construct Reputation was based on the study of Cho, et al. [17]. The items of all constructs were shown in Table I.

Fig. 1 Proposed research model

TABLE I. ITEMS OF CONSTRUCTS

\begin{tabular}{|l|l|}
\hline \multicolumn{1}{|c|}{ Constructs } & \multicolumn{1}{c|}{ Items } \\
\hline \multicolumn{1}{|c|}{ PEOU } & Learning to use the forwarding function in social media would be easy for me. \\
\hline & I find the forwarding function in social media to be easy to use. \\
\hline Reputation & $\begin{array}{l}\text { I find it easy to use forwarding function in social media. } \\
\text { after natural disasters. }\end{array}$ \\
\hline & $\begin{array}{l}\text { I feel that forwarding anti-rumors of natural disasters could enhance my reputation in social } \\
\text { media after natural disasters. }\end{array}$ \\
\hline & $\begin{array}{l}\text { I can receive recognition from others by forwarding anti-rumors of natural disasters in social } \\
\text { media after natural disasters. }\end{array}$ \\
\hline Attitude & $\begin{array}{l}\text { Forwarding anti-rumors of natural disasters in social media after natural disasters is a good } \\
\text { idea. }\end{array}$ \\
\hline & Forwarding anti-rumors of natural disasters in social media after natural disasters is wise. \\
\hline ISAR & $\begin{array}{l}\text { Forwarding anti-rumors of natural disasters in social media after natural disasters is } \\
\text { beneficial. }\end{array}$ \\
\hline & I intend to spread anti-rumors of natural disasters in social media after natural disasters. \\
\hline & I predict I would spread anti-rumors of natural disasters in social media after natural disasters. \\
\hline & I plan to spread anti-rumors of natural disasters in social media after natural disasters. \\
\hline
\end{tabular}

After the questionnaire was designed, we carried out the questionnaire through the Internet.

\section{RESUlTS AND DISCUSSION}

\section{A. Descriptive statistics}

A total of 200 questionnaires were collected and four invalid questionnaires were excluded. In the end, 196 valid questionnaires were obtained. The demographics of participants were shown in Table II.

TABLE II. DEMOGRAPHICS OF PARTICIPANTS

\begin{tabular}{|l|l|l|l|}
\hline \multicolumn{1}{|c|}{ Measure Items } & \multicolumn{1}{c|}{ Frequency } & \multicolumn{1}{|c|}{ Percentage } & $26.5 \%$ \\
\hline Gender & Male & 52 & $73.5 \%$ \\
\hline Age & Female & 114 & $41.3 \%$ \\
\hline & $\leq 19$ & 81 & $58.7 \%$ \\
\hline & $20-29$ & 115 & $0 \%$ \\
\hline Occupation & $30-39$ & 0 & $0 \%$ \\
\hline Time length of social media use & $\geqslant 40$ & 0 & $100 \%$ \\
\hline
\end{tabular}




\begin{tabular}{|l|l|l|l|}
\hline \multicolumn{4}{|c|}{ Table II. cont. } \\
\hline & 6 months - 1 year & 2 & $1 \%$ \\
\hline & 1 year - 2 year & 33 & $16.8 \%$ \\
\hline & $>$ 2 year & 158 & $80.6 \%$ \\
\hline
\end{tabular}

As shown in Table II, in the gender distribution of the respondents, there were 52 males $(26.5 \%)$ and 144 females $(73.5 \%)$. In terms of age distribution, $81(41.3 \%)$ were under the age of 19 , and $115(58.7 \%)$ were aged between 20 and 29 . In time length of social media use, the number using less than 6 months was 3 (1.5\%), 6 months - 1 year (less than 1 year) was 2 (1\%), 1 year to 2 years (less than 2 years) was $33(16.8 \%), 2$ years and above was $158(80.6 \%)$. In occupation, all participants were undergraduate students.

\section{B. Validity and reliability}

A confirmatory factor analysis (CFA) was conducted to examine the validity of all the constructs. The results of CFA were acceptable (AGFI $=0.87, \chi^{2} / d f=2.15, \quad \mathrm{CFI}=0.98$, $\mathrm{IFI}=0.98, \quad \mathrm{NFI}=0.96, \quad \mathrm{SRMR}=0.054, \quad \mathrm{RMSEA}=0.077)$. The Composite Reliability (CR), Average Variance Extracted (AVE), and Cronbach's Alpha were given in Table III.

TABLE III. ItEM LOADINGS, ALPHA VALUES, CR AND AVE

\begin{tabular}{|l|l|l|c|c|l|}
\hline Constructs & Items & Loadings & a & CR & AVE \\
\hline PEOU & PEOU1 & 0.77 & 0.81 & 0.83 & 0.62 \\
\hline & PEOU2 & 0.86 & & & \\
\hline & PEOU3 & 0.72 & & & \\
\hline Reputation & REPU1 & 0.82 & 0.89 & 0.89 & 0.73 \\
\hline & REPU2 & 0.87 & & & \\
\hline & REPU3 & 0.87 & & & \\
\hline Attitude & ATT1 & 0.83 & 0.88 & 0.88 & 0.71 \\
\hline & ATT2 & 0.88 & & & \\
\hline & ATT3 & 0.82 & & & \\
\hline ISAR & ISAR1 & 0.91 & 0.96 & 0.96 & 0.88 \\
\hline & ISAR2 & 0.98 & & & \\
\hline & ISAR3 & 0.93 & & & \\
\hline
\end{tabular}

As shown in Table III, AVE and CR for each construct exceeded 0.5 and 0.7 respectively, indicated the measure had a good convergent validity [18]. Furthermore, all values of Cronbach's Alpha were greater than 0.7, which also indicated that internal consistency of all constructs were acceptable.

\section{Hypotheses testing}

LISREL 8.7 program was conducted to process path analysis. The fitness indices indicated that the research model had a good fitness (AGFI $=0.87, \chi^{2} / d f=2.11$, CFI=0.98, $\mathrm{IFI}=0.98, \mathrm{NFI}=0.96, \mathrm{NNFI}=0.97, \mathrm{SRMR}=0.059, \mathrm{RMSEA}=$ 0.076). The path coefficients and significance were presented in Fig.2.

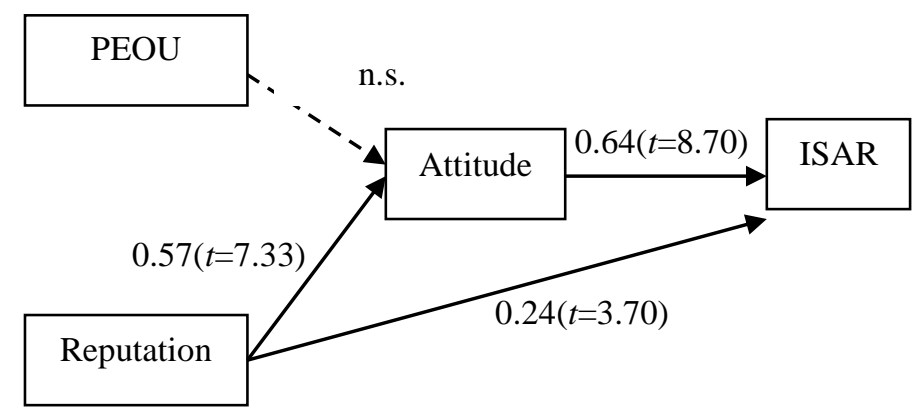

Fig. 2 Path coefficients and significance of the research model

As shown in Fig. 2, Attitude had a significant positive effect on Intention of Spreading Anti-Rumors, that is, $\mathrm{Hl}$ was supported by the data. Perceived Ease of Use had no causal relationships with Attitude. Therefore, $\mathrm{H} 2$ was not supported. Reputation had a significant positive impact on Attitude and Intention of Spreading Anti-Rumors, that is, $H 3$ and $H 4$ was supported by the data.

\section{Discussion}

The positive influence of attitude on anti-rumors is positively causing intention to spread anti-rumors of natural disasters. It is consistent with the previous studies. However, perceived ease of use has no significant effect on the attitudes of spreading anti-rumors. It is contrary to the results of previous study of information system use [6, 19, 20]. There are two possible reasons. Firstly, different to information system used in the organizational context, the user experience of social media is often higher than the former. Users are often able to skillfully use various functions of social media, including forwarding. Secondly, in our study, respondents are college students. Young college students are willing to adopt new technology, and often have good information technology use ability.

The results of this study showed that pursuit of reputation has significant positive impact on the attitude and intention of spreading anti-rumors of natural disasters. This result is consistent with the existing research results. Our approach to increase users' participation forwarding the anti-rumors information is based on accentuation and reputation [21]. By motivating many users we want to increase the community so that cross-checking takes place and false information is automatically sorted out [10]. That such an approach of member-maintained communities increases the quantity and quality of the anti-rumors information was affirmed [22]. In pursuit of personal reputation, people would spread anti-rumors information positively. 


\section{CONCLUSION}

Based on Technology Acceptance Model, this paper investigated users' intention of spreading anti-rumors of natural disasters. Our empirical results reveal that Reputation has significant positive effects on Attitude and Intention of spreading anti-rumors of natural disasters, while, Perceived Ease of Use has no significant impact on Attitude toward spreading anti-rumors of natural disasters.

This study has important practical implications for dispelling rumors in natural disasters. This study shows that reputation has significant impact on attitude and intention of spreading anti-rumors of natural disasters. Therefore, social media operators could set some virtual medals or titles to encourage the behavior of spreading anti-rumors in the context of natural disasters. Moreover, to further promote social acceptance of spreading anti-rumors in social media, the government and media should promote the concept "spreading anti-rumors is a kind of virtue" to the public.

The limitation of this study is that the participants were undergraduate students. As a result, the findings of this study may not be generalized to the other participants. Therefore, future researches can generalize our results to different groups of people.

\section{ACKNOWLEDGMENT}

This study was supported by Department of Education of Guangdong Province, China (2015WQNCX014).

\section{REFERENCES}

[1] P. Ozturk, H. Li, and Y. Sakamoto, "Combating rumor spread on social media: The effectiveness of refutation and warning," in System Sciences (HICSS), 2015 48th Hawaii International Conference on, 2015, pp. 2406-2414.

[2] Y. Chun, H. S. Hwang, and C. S. Kim, "A study on the extraction of damage locations using twitter messages," Computer Applications for Software Engineering, Disaster Recovery, and Business Continuity, pp. 218-224, 2012.

[3] A. H. Tapia, K. A. Moore, and N. J. Johnson, "Beyond the trustworthy tweet: A deeper understanding of microblogged data use by disaster response and humanitarian relief organizations," in ISCRAM, 2013.

[4] F. Liu, A. Burton-Jones, and D. Xu, "Rumors on Social Media in disasters: Extending Transmission to Retransmission," in PACIS, 2014, p. 49.

[5] T. Hashimoto, T. Kuboyama, and Y. Shirota, " Rumor analysis framework in social media," presented at the 2011 IEEE Region 10 Conference Tencon 2011, Bali, 2011.

[6] F. D. Davis, "Perceived usefulness, perceived ease of use, and user acceptance of information technology," Management Information Systems Quarterly, vol. 13, pp. 319-340, 1989.
[7] A. Ajili, S. Salehi, K. Rezaei-moghaddam, D. Hayati, and F. Karbalaee, "Estimating the model of investigating attitude and intention in the usage of variable rate irrigation technology," American Journal of Experimental Agriculture, vol. 2, p. 542, 2012.

[8] A. M. Adrian, S. H. Norwood, and P. L. Mask, "Producers' perceptions and attitudes toward precision agriculture technologies," Computers and electronics in agriculture, vol. 48, pp. 256-271, 2005.

[9] B. S. McGowan, M. Wasko, B. S. Vartabedian, R. S. Miller, D. D. Freiherr, and M. Abdolrasulnia, "Understanding the factors that influence the adoption and meaningful use of social media by physicians to share medical information," Journal of medical Internet research, vol. $14,2012$.

[10] B. Hoisl, W. Aigner, and S. Miksch, "Social rewarding in wiki systems Motivating the community," in Online Communities and Social Computing: Second International Conference, OCSC 2007, Held as Part of HCI International 2007, Beijing, China, July 22-27, 2007. Proceedings, D. Schuler, Ed., ed Berlin, Heidelberg: Springer Berlin Heidelberg, 2007, pp. 362-371.

[11] S. Kim, E.-K. Na, and M.-H. Ryu, "Factors affecting user participation in video UCC (User-Created Contents) services," in Communities and Technologies 2007, ed: Springer, 2007, pp. 209-224.

[12] X. Yang, Y. Li, C.-H. Tan, and H.-H. Teo, "Students' participation intention in an online discussion forum: Why is computer-mediated interaction attractive?," Information \& Management, vol. 44, pp. 456466, 2007.

[13] O. Nov, "What motivates wikipedians?," Communications of the ACM, vol. 50, pp. 60-64, 2007.

[14] Y. Wang and D. R. Fesenmaier, "Assessing motivation of contribution in online communities: An empirical investigation of an online travel community," Electronic markets, vol. 13, pp. 33-45, 2003.

[15] I. Dastan, "Factors affecting the adoption of mobile payment systems: an empirical analysis," Emerging Markets Journal, vol. 6, p. 17, 2016.

[16] V. Venkatesh and F. D. Davis, "A theoretical extension of the technology acceptance model: Four longitudinal field studies," Management science, vol. 46, pp. 186-204, 2000.

[17] H. Cho, M. Chen, and S. Chung, "Testing an integrative theoretical model of knowledge - sharing behavior in the context of Wikipedia," Journal of the Association for Information Science and Technology, vol. 61, pp. 1198-1212, 2010.

[18] R. P. Bagozzi and Y. Yi, "On the evaluation of structural equation models," Journal of the academy of marketing science, vol. 16, pp. 7494, 1988.

[19] A. C. Azmi and N. L. Bee, "The Acceptance of the e-Filing System by Malaysian Taxpayers: A Simplified Model," Electronic Journal of $e$ Government, vol. 8, 2010.

[20] P. A. Ratna and S. Mehra, "Exploring the acceptance for e-learning using technology acceptance model among university students in India," International Journal of Process Management and Benchmarking, vol. 5 , pp. 194-210, 2015.

[21] T. Chesney, "An empirical examination of Wikipedia's credibility," First Monday, vol. 11, 2006.

[22] D. Cosley, D. Frankowski, S. Kiesler, L. G. Terveen, and J. Riedl, "How oversight improves member-maintained communities," in human factors in computing systems, 2005, pp. 11-20. 